\title{
Sebaran Mineral Feromagnetik Di Perairan Delta Sungai Bodri, Kendal Petrus Subardjo $^{{ }^{*}}$, Sri Yulina Wulandari ${ }^{1}$, Muhamad Adnan Kurnianto ${ }^{2}$, Sugeng Widada ${ }^{1}$, Rikha Widiaratih ${ }^{1}$ \\ ${ }^{1}$ Departemen Oseanografi, Fakultas Perikanan dan Ilmu Kelautan, Universitas Diponegoro, Semarang ${ }^{2}$ Program Sarjana Departemen Oseanografi, Fakultas Perikanan dan Ilmu Kelautan Jalan Prof. Soedarto, S.H., Tembalang, Telp/Fax (024)7474698 Semarang 50275 \\ Email :*petrus_soebardjo@yahoo.com
}

\begin{abstract}
Abstrak
Mineral feromagnetik atau biasa disebut pasir hitam merupakan salah satu mineral berat yang berasal dari aktivitas vulkanik. Pemanfaatan mineral ini memegang peranan cukup penting dalam kehidupan sehari-hari, mulai dari aspek industri, elektronik, rumah tangga, otomotif, hingga digunakan sebagai bahan pengobatan kanker dalam bidang kedokteran. Delta sungai Bodri yang alirannya bersumber dari gunung Ungaran serta laju sedimentasi yang cukup tinggi menjadi wilayah yang tepat untuk dilakukan penelitian ini. Penelitian ini dilakukan untuk mengetahui seberapa besar kandungan, pola sebaran serta faktor-faktor apa saja yang berpengaruh terhadap kandungan mineral feromagnetik yang terdapat pada sedimen dasar di delta sungai Bodri. Untuk mengetahui kandungan mineral feromagnetik, digunakan teknik analisa sederhana terhadap sampel sedimen menggunakan magnet dan mikroskop di laboratorium. Arus sejajar pantai diperhitungkan untuk diketahui pengaruhnya terhadap sebaran mineral feromagnetik. Hasil analisa ini menunjukkan kandungan sedimen yang tersebar secara terpola dari dalam sungai, muara, hingga sisi delta dengan kandungan tertinggi pada sungai sebesar 35,04 \%. Pada depan muara sungai mineral ini tidak terdeteksi, kemudian terdeteksi kembali pada sisi-sisi delta, baik pada bagian barat maupun bagian timur yang kadarnya bervariasi sekitar 2-5\%. Hal ini menjelaskan adanya hubungan arus sejajar pantai terhadap sebaran mineral feromagnetik di wilayah delta sungai Bodri.
\end{abstract}

\section{Kata kunci: Arus sejajar pantai, Delta sungai Bodri, Mineral feromagnetik, Sebaran, Sedimen,}

\begin{abstract}
Ferromagnetic minerals or known as black sand is one of the heavy minerals which is derived from volcanic activity. This mineral utilization plays an important role in everyday life, ranging from aspects of industry, electronics, household, automotive, even used as a treatment of cancer in the field of medicine. The Bodri River Delta, which sourced from Ungaran Mountain and a high sedimentation rate, is the right area for this research. This research was conducted to find out how big the content, the pattern of distribution and any factors that affect the ferromagnetic mineral content found in the basic sediment in the Bodri river delta. To know the mineral content of ferromagnetic, used simple analysis technique to sediment sample using magnet and microscope in laboratory. Longshore currents are taken into account to determine its effect on the distribution of the mineral ferromagnetic. The results of this analysis show that the sediment content is scattered patterned from the river, estuary, to the delta side with the highest content in the river of 35.04\%. In front of the river mouth, this mineral is undetectable. Then detect again on the sides of the delta, both on the western and eastern parts which levels vary about 2-5\%. This explains the existence of a longshore current linkage to the ferromagnetic mineral distribution in the Bodri river delta region.
\end{abstract}

\section{Keywords: Bodri river delta, Distribution, Longshore current, Mineral feromagnetic, Sedime}




\section{PENDAHULUAN}

Wilayah Indonesia berada diantara lima lempeng, yaitu Lempeng Pasifik, Lempeng Eurasia, Lempeng Australia, Lempeng India dan Lempeng Filipina. Hal ini yang menyebabkan Indonesia memiliki banyak gunung berapi. Gunung berapi dapat menjadi sumber bencana yang mengerikan, tetapi di sisi lain, hal ini juga bisa menjadi sangat menguntungkan. Aktivitas vulkanik dapat menghasilkan mineral-mineral yang sangat bermanfaat serta bernilai ekonomis. Saat ini mineral telah dimanfaatkan dalam berbagai bidang kehidupan, mulai dari perkakas rumah tangga, otomotif, keperluan militer, bidang kesehatan hingga perhiasan semuanya mengandung mineral (Revia, 2015). Salah satu mineral yang banyak dimanfaatkan ialah mineral feromagnetik. Mineral ini mempunyai sifat kemagnetan yang sangat kuat dan merupakan magnet alami, merupakan bahan utama pembuatan besi dan baja. Mineral feromagnetik diantaranya magnetite, hematite dan ilminite. Mineral magnetite digunakan sebagai bahan dasar tinta kering/toner untuk mesin fotokopi, hematite sebagai zat warna, ilminite sebagai zat warna kualitas tinggi untuk dalam industri cat, trekstil, dan sebagai sunscreen karena dapat mengabsorbsi sinar ultraviolet (Yulianto et al. dalam Gunawan et al., 2014). Sifat-sifat mineral magnetik ditentukan oleh magnetisasi saturasi, magnetisasi remanen, medan koersifitas, dan suseptibilitas magnetik. Dalam industri magnet, suseptibilitas merupakan salah satu faktor penentu kualitas bahan baku. Suseptibilitas magnetik adalah perbandingan kuat medan magnet induksi dalam sampel dengan medan magnet luar yang diberikan (Gunawan et al., 2014).

Mineral-mineral feromagnetik berasal dari aktivitas vulkanik tertranspor melalui sungai-sungai dari hulu hingga ke hilir. Sungai Bodri merupakan salah satu sungai yang terdapat di kota Kendal. Sungai ini cukup terkenal karena terdapat delta yang tidak dapat ditemukan di setiap muara sungai. Hanya beberapa sungai dengan kriteria tertentu yang memiliki delta. Sungai Bodri berasal dari dua wilayah hilir, yaitu gunung Ungaran dan pegunungan Dieng. Dua wilayah hilir inilah yang sangat berpengaruh terhadap kandungan material sedimen yang terdapat pada sungai Bodri. Potensi sumberdaya alam dan letaknya yang strategis menjadikan Sungai Bodri dirasa tepat untuk dijadikan sebagai daerah kajian penelitian dan eksplorasi.

Berbagai penelitian telah dilakukan di wilayah delta sungai Bodri, diantaranya perubahan garis pantai, laju sedimentasi, transpor sedimen, jenis sedimen berdasarkan ukuran butir dan arus sejajar pantai yang dominan dari arah timur laut (Atmodjo, 2010). Perlu dikembangkan lebih lanjut berdasarkan penelitian-penelitian yang sudah ada untuk mengetahui potensi sumberdaya alam yang terdapat di delta sungai Bodri, untuk itulah dilakukan penelitian tentang kandungan mineral feromagnetik, bagaimana pola sebarannya serta faktor-faktor apa saja yang mempengaruhi sebaran sebaran sedimen dasar di perairan delta sungai Bodri.

\section{MATERI DAN METODE}

Materi yang digunakan dalam penelitian ini adalah data primer, berupa sampel sedimen dan data gelombang. Sebagai data sekunder, yaitu data arah dan kecepatan angin selama 10 tahun (2006-2015) dari ECMWF. Metode ialah cara-cara ilmiah yang dilakukan dalam mendapatkan data untuk suatu keperluan. Metode yang digunakan dalam penelitian ini ialah metode kuantitatif, yaitu metode yang digunakan untuk meneliti sampel tertentu, menggunakan instrument penelitian, analisa secara kuantitatif, yang bertujuan untuk menguji hipotesa penelitian yang telah ditentukan sebelumnya (Sugiyono, 2009).

\section{Pengambilan dan Analisa Sampel Sedimen}

Sampel diambil menggunakan sediment grab pada 12 stasiun pengambilan sampel yang telah ditentukan sebelumnya. Stasiun pengambilan sampel dapat dilihat pada gambar 1. Setelah itu, sampel sedimen yang telah diambil dikeringkan untuk selanjutnya dianalisa lebih lanjut di laboratorium untuk mengetahui kandungan mineral feromagnetik. Sampel yang telah kering kemudian diambil dari masingmasing stasiun 10 gram sampel, lalu ditaruh pada wadah secara merata. Magnet yang sebelumnya telah dibungkus dengan plastik diedarkan sekitar 1-2 cm diatas permukaan sampel untuk menarik mineral feromagnetik pada sampel. Selanjutnya, mineral feromagnetik yang menempel dimasukkan ke dalam plastik sampel yang berartnya telah ditimbang sebelumnya. Setelah dipisahkan dari sedimen lain, sampel dilihat dibawah mikroskop pada perbesaran 40 kali dan 100 kali untuk dilihat lebih lanjut apakah 
masih ada sedimen lain yang ikut terbawa. Tahap terakhir, dilakukan penimbangan untuk diketahui berat kemudian dihitung persentasi kandungan feromagnetik pada sampel. Kandungan mineral feromagnetik pada sampel dapat diketahui dengan rumus sebagai berikut :

$$
\text { Kadar mineral feromagnetik }=\frac{\text { makhir }}{\text { mawal }} \times 100 \%
$$

Keterangan :

m akhir : massa akhir sedimen setelah dilakukan analisa (gram)

$\mathrm{m}$ awal : massa awal sebelum dilakukan analisa (gram)

(Gunawan et al., 2014)

\section{Pengukuran Data Gelombang di Lapangan}

Pengukuran data gelombang dilakukan secara konvensional dengan menggunakan palem gelombang berskala $1 \mathrm{~cm}$ untuk ketinggian dan jam tangan yang memiliki fitur stopwatch untuk menghitung periode gelombang. Sehari sebelum mengukur gelombang diperlukan pengukuran kecepatan dan arah angin berhembus selama 12 jam (06.00-18.00), dengan interval 30 menit untuk menentukan waktu yang efektif dalam pengukuran gelombang (Triatmodjo, 1999). Terjadinya gelombang di laut sangat kompleks dan memiliki bentuk yang tidak teratur dengan tinggi dan periodenya pun tidak konstan. Oleh karena itu, di dalam analisa serta pengolahan data gelombang ini digunakan gelombang representatif, yaitu penyaringan data-data ketinggian dan periode gelombang individu yang dapat mewakili satu spektrum gelombang (Triatmodjo, 1999).

Gelombang representatif $\mathrm{H}_{33}$ atau biasa disebut tinggi gelombang signifikan $\left(\mathrm{H}_{\mathrm{s}}\right)$ ialah yang paling banyak digunakan karena penggunaan 33\% persen data tertinggi dari total data yang dimiliki dianggap efisien. Disamping itu, $\mathrm{H}_{33}$ cukup baik mewakili keseluruhan data tersebut tanpa perlu mengolah semua data yang diperoleh. Persamaan gelombang signifikan dan periode gelombang signifikan dapat ditulis sebagai berikut :

$$
\begin{aligned}
& H_{33}=\frac{H_{1}+H_{2}+\cdots+H_{n}}{n} \\
& T_{33}=\frac{T_{1}+T_{2}+\cdots+T_{n}}{n} \\
& \text { Keterangan } \\
& \mathrm{H}_{33} \quad \text { : ketinggian gelombang signifikan }(\mathrm{cm}) \\
& \mathrm{T}_{33} \quad \text { : periode gelombang signifikan }(\mathrm{cm}) \\
& \mathrm{n} \quad \text { : jumlah data }
\end{aligned}
$$

\section{Analisa dan Peramalan Data Gelombang ECWF}

(Handoyo et al., 2015)

Data angin selama 10 tahun yang telah di download dari situs ECMWF (European Centre for Medium-Range Weather Forecasts), diperiksa dan dikoreksi menggunakan perangkat lunak Ocean Data View 4 kemudian diinput kedalam Microsoft excel 2013. Analisa data angin selama 10 tahun ini menggunakan mawar angin untuk lebih memudahkan dalam menganalisa data angin, seperti kecepatan serta arah hembusan angin dominan yang terjadi di wilayah delta Bodri pada tiap-tiap musimnya. Data angin ECMWF yang telah dikoreksi pada tahap analisa data angin juga dapat digunakan untuk meramalkan gelombang dengan metode Sugianto (2014). Dalam hal ini kecepatan angin diklasifikasikan mejadi beberapa kelompok dan data angin yang dapat digunakan adalah yang kecepatannya di atas 10 knot. Untuk mendapatkan tinggi gelombang signifikan $\left(\mathrm{H}_{\mathrm{s}}\right)$ serta periode gelombang signifikan $\left(\mathrm{T}_{\mathrm{s}}\right)$ menggunakan persamaan sebagai berikut:

$$
\begin{gathered}
\mathrm{H}_{\mathrm{s}}=0,0016 \mathrm{U}^{2}+0,0406 \mathrm{U} \\
\mathrm{T}_{\mathrm{s}}=0,15 \mathrm{U}+2,982 \\
\text { Keterangan : } \\
\mathrm{U}: \text { Kecepatan angin (knot) }
\end{gathered}
$$




\section{Validasi Data Gelombang}

Data gelombang hasil peramalan gelombang merupakan data yang bersifat pendekatan terhadap data gelombang yang terjadi sebenarnya. Data tesebut menjadi tidak relevan apabila tidak ada pembanding nilai kejadian sesungguhnya agar diketahui seberapa baik data hasil peramalan gelombang tersebut. Oleh sebab itu, sangat perlu dilakukan validasi data gelombang hasil peramalan. Sebagai pembanding untuk validasi, digunakan data gelombang real hasil pengukuran gelombang signifikan di lapangan. Metode validasi yang digunakan untuk mengetahui keakuratan data tersebut ialah metode persentase bias (PB). Persamaan PB menurut Moriasi et al. (2007) sebagai berikut:

$$
P B=\frac{\left(\sum D-\sum M\right)}{\sum D} \times 100 \%
$$

Keterangan:

$\mathrm{D}$ : data pengukuran lapangan

$\mathrm{M}$ : data hasil peramalan

\section{HASIL DAN PEMBAHASAN}

Pada pengukuran gelombang di lapangan diperoleh 540 data ketinggian gelombang dan periode gelombang yang nilainya fluktuatif. Pada awal pengukuran gelombang tergolong rendah, kemudian mulai naik pada hari kedua dan ketiga pengukuran. Kondisi di lapangan selama 3 hari pengukuran sangat cerah dengan suhu sekitar $30^{\circ}$ hingga $32^{\circ}$ celcius. Hasil pengukuran ketinggian gelombang tertinggi ialah $42 \mathrm{~cm}$ dan terendah $9 \mathrm{~cm}$ dengan ketinggian gelombang signifikan rerata $29,86 \mathrm{~cm}$. Periode gelombang terukur di lapangan terlama 7,95 detik dan terendah 1,09 detik dengan rerata periode gelombang signifikan 3,54 detik. Hasil pengukuran data gelombang di lapangan lebih jelasnya ditunjukkan dengan Gambar 1 berikut ini.

A

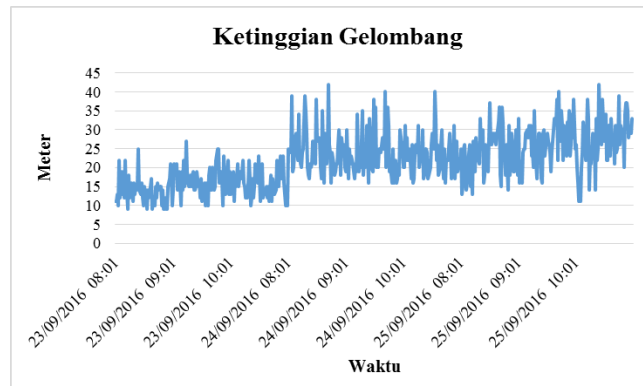

$\mathrm{B}$

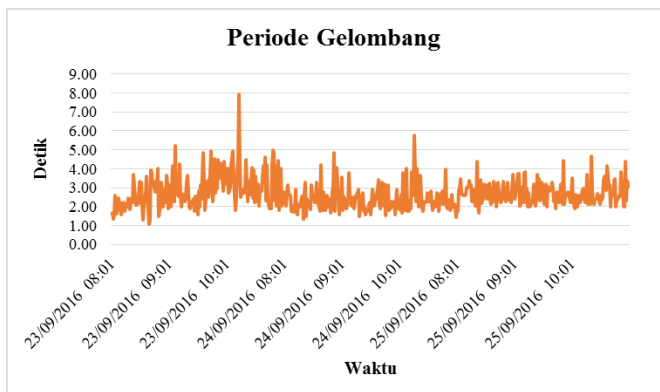

Gambar 1. Ketinggian gelombang (A) dan Periode gelombang (B) hasil pengukuran lapangan.

Analisa data angin selama 10 tahun menghasilkan pola distribusi angin yang berbeda setiap musimnya. Pada musim barat, angin dominan bergerak dari arah barat laut. Kecepatan angin terbesar juga berasal dari arah barat laut dengan frekuensi kejadian mencapai 34,9\% dari total angin yang berhembus setiap musim barat (Desember-Februari) sepanjang tahun 2006 hingga 2015. Musim peralihan I, distribusi angin terjadi hampir merata dari segala arah, dengan frekuensi kejadian 15,8\% yang dominan berhembus dari arah Tenggara mendekati Selatan (sekitar $160^{\circ}$ ) sementara kecepatan angin terkuat (diatas $10 \mathrm{knot}$ ) justru terjadi dari arah yang beralawanan, yaitu dari arah barat laut. Dinamika angin pada musim timur cenderung statis dominasi dan kecepatan angin tertinggi sama-sama bergerak dari arah tenggara dengan frekuensi hingga 32,5\%. Musim Selanjutnya ialah musim peralihan II yang dominasi pola distribusi anginnya tepat berasal dari arah Tenggara dengan frekuensi kejadian mencapai $16,9 \%$, namun kecepatan angin terkuat berhembus dari arah tenggara sedikit timur. Lebih jelasnya hasil analisa data angin ditunjukkan dalam Gambar 2 dalam bentuk mawar angin. 
A
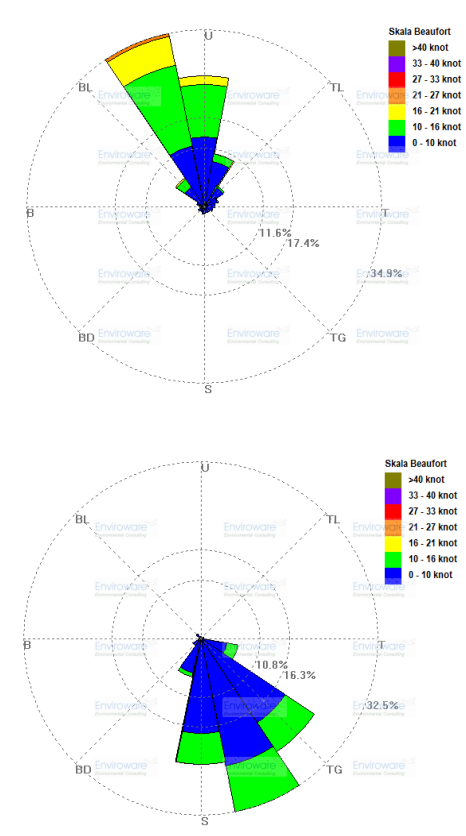

C
B
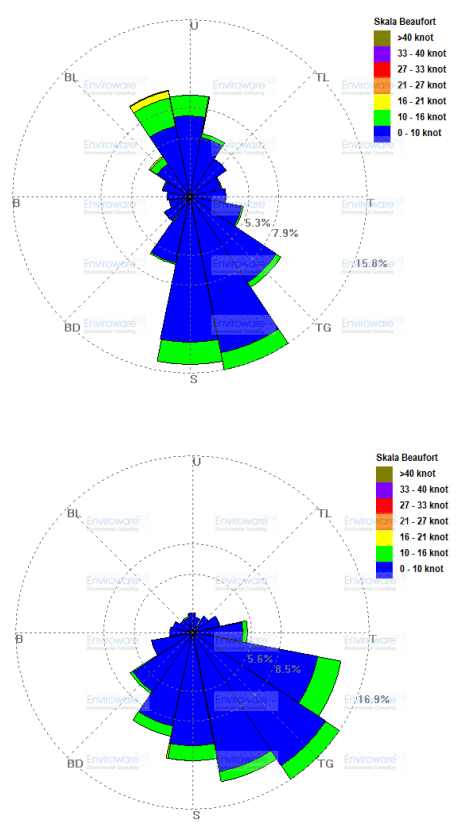

D

Gambar 2. Distribusi angin perairan Semarang pada musim barat (A), Peralihan 1 (B), Timur (C), serta peralihan $2(\mathrm{D})$

Peramalan gelombang berdasarkan data angin selama 10 tahun menunjukkan penjalaran gelombang secara keseluruhan yang tertinggi pada musim barat dengan ketinggian maksimum mencapai $1,97 \mathrm{~m}$. Ketinggian gelombang signifikan rerata pada musim barat $0,88 \mathrm{~m}$ dengan ketinggian gelombang signifikan minimum $0,57 \mathrm{~m}$. Ketinggian gelombang maksimum pada peralihan I setinggi 1,76 m dengan gelombang signifikan rerata $0,75 \mathrm{~m}$ dan ketinggian signifikan minimum yang tercatat $0,57 \mathrm{~m}$. Pada musim timur gelombang cukup tinggi bergerak ke arah barat dengan ketinggian maksimum 1,22 m, gelombang signifikan rerata $0,68 \mathrm{~m}$ serta ketinggian signifikan minimum $0,57 \mathrm{~m}$. Musim peralihan II memiliki ketinggian gelombang yang cukup rendah dibanding musim lainnya yang ketinggian maksimum hanya $1,07 \mathrm{~m}$, ketinggian gelombang signifikan rerata $0,65 \mathrm{~m}$ dan ketinggian signifikan minimum gelombang $0,57 \mathrm{~cm}$.

Peramalan gelombang menunjukkan lama periode gelombang signifikan rerata yang hampir sama hanya berbeda sepersekian detik saja. Periode gelombang terlama tetap sama dengan ketinggian gelombang, yaitu terjadi pada musim barat dengan periode terlama 6,58 detik dengan periode signifikan rerata 4,97 detik dan periode signifikan minimum 4,39 detik. Periode gelombang signifikan pada musim peralihan I memiliki periode maksimum 6,32 detik, periode signifikan rerata 4,73 detik dan periode minimum 4,39 detik. Pada musim timur, periode gelombang signifikan rerata selama 4,61 detik dengan periode gelombang signifikan aksimum dan minimum secara berurutan 5,55 detik dan 4,39 detik. Periode gelombang terkecil terjadi pada musim peralihan II dengan gelombang signifikan rerata 4,56 detik, periode maksimum 5,31 detik dan periode minimumnya 4,39 detik. Hasil peramalan gelombang secara keseluruhan ditunjukkan dengan Gambar 3. 
A

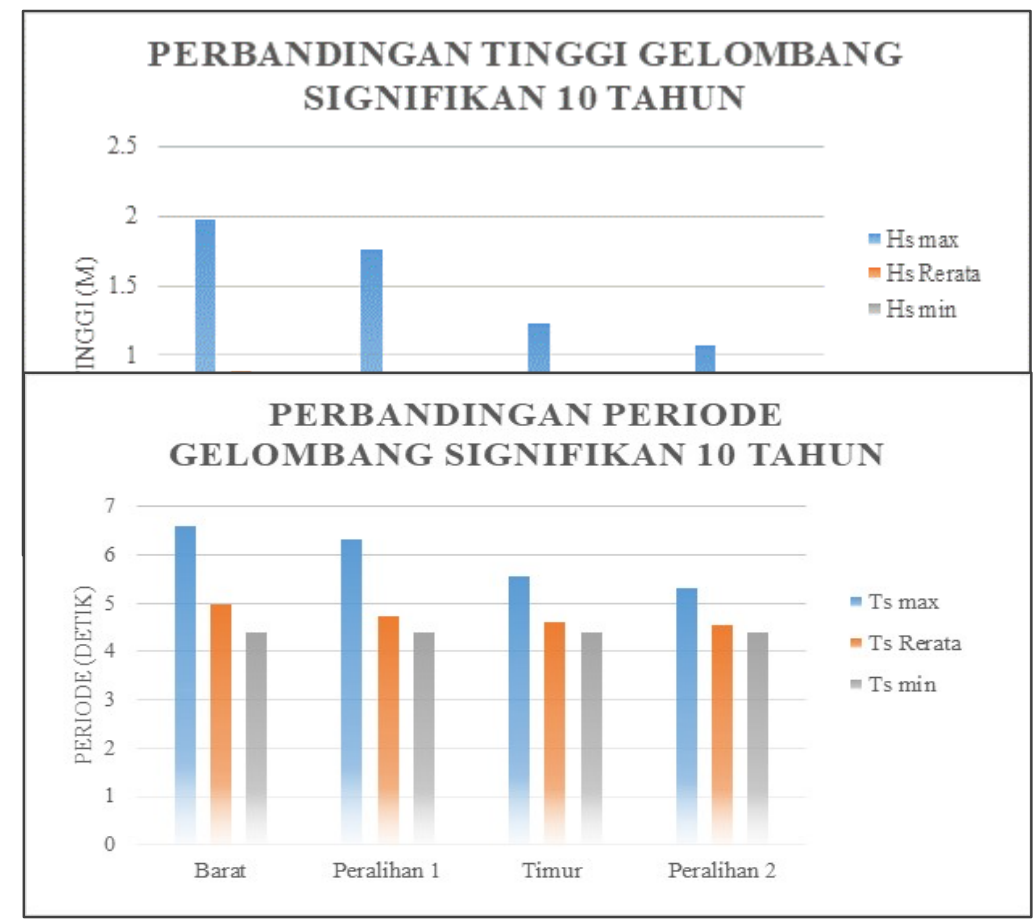

Gambar 3. Peramalan ketinggian (A) dan periode (B) gelombang signifikan tiap musim selama 10 tahun

Arus sejajar pantai yang terjadi di delta sungai Bodri dominan terjadi pada musim barat dengan kecepatan hingga $2,64 \mathrm{~m} /$ detik. Arah datang gelombang dari sudut $340^{\circ}$ dengan sudut gelombang pecah $-42,79^{\circ}$. Pada musim peralihan 1 kecepatan arus sejajar pantai sebesar $1,08 \mathrm{~m} /$ detik ke arah timur dengan arah datang gelombang $343^{\circ}$ dan sudut gelombang pecah $-40,88^{\circ}$. Pada musim timur kecepatan gelombang mencapai $0,21 \mathrm{~m} /$ detik ke arah barat dengan arah datang gelombang $101^{\circ}$ dan membentuk sudut gelombang pecah $6,42^{\circ}$. Musim peralihan 2 kecepatan arus sejajar pantai cukup rendah, yaitu 0,24 $\mathrm{m} /$ detik dari arah timur dengan arah datang gelombang $100^{\circ}$ dan sudut gelombang pecahnya $6,81^{\circ}$. Hasil perhitungan arus sejajar pantai tiap musimnya ditunjukkan pada Tabel 1.

Tabel 1. Hasil perhitungan arus sejajar pantai tiap musim

\begin{tabular}{lcccc}
\hline \multicolumn{1}{c}{ Parameter Gelombang } & \multicolumn{4}{c}{ Musim } \\
& Barat & Peralihan 1 & Timur & Peralihan 2 \\
\hline $\begin{array}{l}\text { Tinggi Gelombang signifikan } \\
\left(\mathrm{H}_{\mathrm{s}}\right)\end{array}$ & $1,97 \mathrm{~m}$ & $1,76 \mathrm{~m}$ & $1,22 \mathrm{~m}$ & $1,07 \mathrm{~m}$ \\
Periode Gelombang & $6,598 \mathrm{det}$ & $6,32 \mathrm{det}$ & $5,55 \mathrm{det}$ & $5,31 \mathrm{det}$ \\
signifikan $\left(\mathrm{T}_{\mathrm{s}}\right)$ & $-51^{\circ}$ & $-54^{\circ}$ & $8^{\circ}$ & $9^{\circ}$ \\
Sudut datang gelombang $\left(\alpha_{0}\right)$ & $-42,79^{\circ}$ & $-40,88^{\circ}$ & $6,42^{\circ}$ & $6,81^{\circ}$ \\
Sudut gelombang pecah $(\alpha \mathrm{b})$ & $-2,64 \mathrm{~m} / \mathrm{det}$ & $-1,08 \mathrm{~m} / \mathrm{det}$ & $0,21 \mathrm{~m} / \mathrm{det}$ & $0,24 \mathrm{~m} / \mathrm{det}$ \\
\hline Kecepatan Longshore $(\mathrm{v})$ & & &
\end{tabular}

Validasi peramalan data gelombang signifikan rerata dengan ketinggian gelombang signifikan pengukuran di lapangan secara langsung dilakukan pada waktu yang sama. Hasilnya, nilai error antara tinggi gelombang signifikan peramalan dengan tinggi gelombang pengukuran di lapangan sebesar 6,89 $\%$. Hasil validasi periode gelombang signifikannya sebesar $7,11 \%$. Perbandingan validasi data gelombang dapat dilihat pada Tabel 2 . 
Tabel 2. Hasil validasi data gelombang menggunakan persentase bias (PB)

\begin{tabular}{ccc}
\hline & Tinggi Gelombang Signifikan & Tinggi Gelombang Signifikan \\
$(\mathrm{Hs})$ & $(\mathrm{Ts})$ \\
\hline Pengukuran & $29.86 \mathrm{~cm}$ & 3.54 detik \\
Peramalan & $31.92 \mathrm{~cm}$ & 3.79 detik \\
PB & $6,89 \%$ & $7,11 \%$ \\
\hline
\end{tabular}

Hasil pengujian terhadap 12 sampel sedimen yang diambil di delta sungai Bodri menunjukkan, bahwa kandungan mineral feromagnetik terbesar terdapat di stasiun 12 dengan kadar 35,04\%. Pada stasiun 1, 2 dan 3 terletak di bagian barat delta. Kandungan mineral feromagnetik terdeteksi pada stasiun 1 sebesar 4,75\%. Pada stasiun 2 dengan kandungan 2,21\% dan stasiun 3 dengan 5,45\%. Di sisi utara delta terdapat kandungan mineral feromagnetik terendah tepatnya stasiun 4 dan 8 yang sama sekali tidak terdeteksi dan stasiun 5 hanya sebesar $0,19 \%$. Pada muara delta, kandungan mineral feromagnetik cukup tinggi dengan kandungan $10,03 \%$ pada titik 6 dan semakin ke arah sungai kandungan semakin meningkat dengan kandungan di stasiun 7 sebesar 11,59\% dan tertinggi di dalam sungai pada stasiun 12 hingga mencapai 35,04\%. Pada sisi timur delta kandungan mineral feromagnetik sebesar $2,64 \%$ pada stasiun $9,2,43 \%$ pada stasiun 10 dan hanya $0,88 \%$ pada stasiun 11 . Hasil lebih lengkapnya divisualisasikan pada gambar 4 , yaitu peta sebaran mineral feromagnetik di perairan delta sungai Bodri.

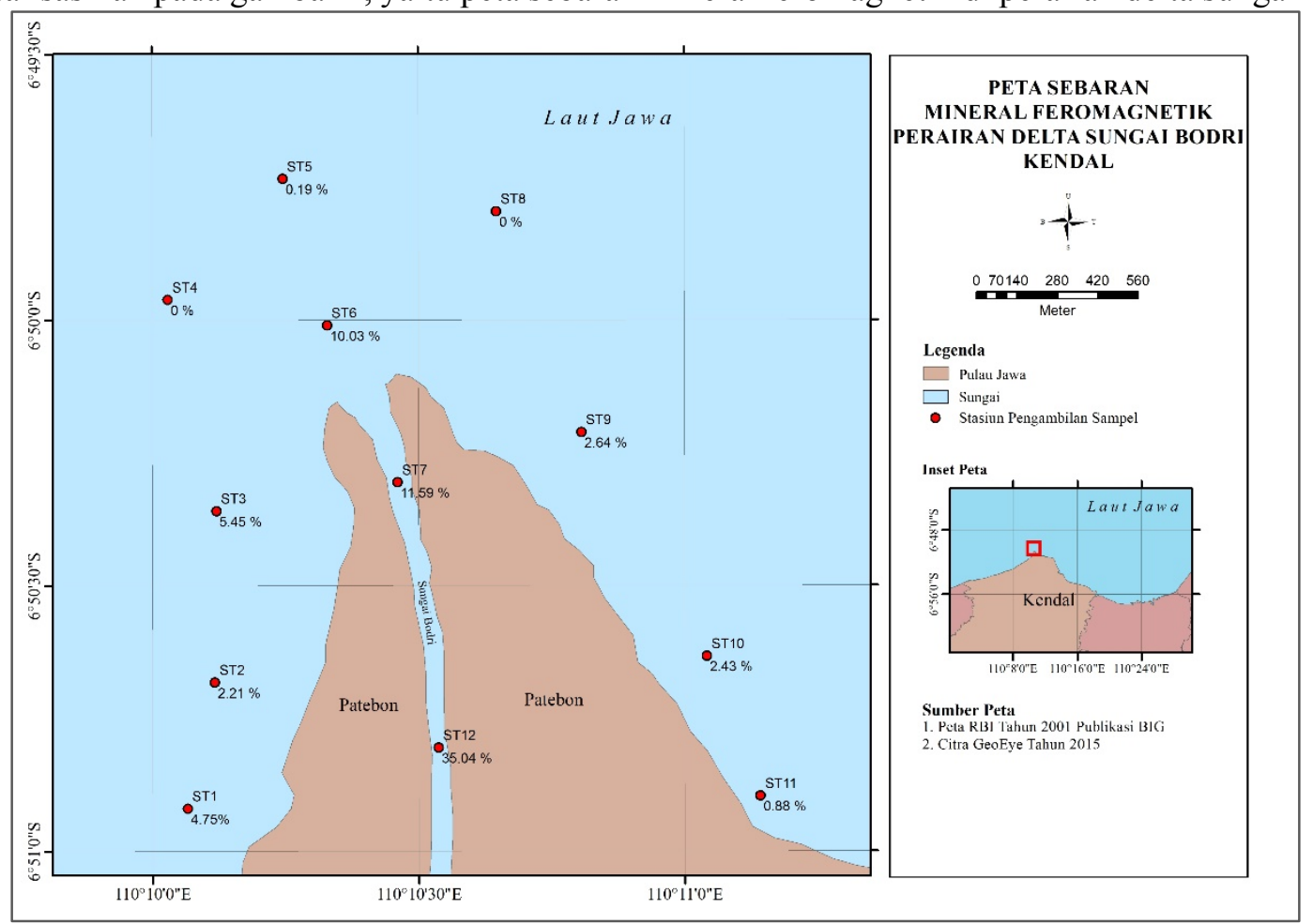

Gambar 4. Peta sebaran mineral feromagnetik di perairan delta sungai Bodri

Gelombang hasil pengukuran menunjukkan ketinggian signifikan yang rendah karena dilakukan pada musim peralihan. Kejadian ini sesuai dengan peramalan gelombang yang dilakukan berdasarkan data angin selama 10 tahun (2006-2015) yang menunjukkan, bahwa gelombang paling kecil terjadi pada musim peralihan 2. Validasi data gelombang peramalan terhadap data gelombang hasil pengukuran di lapangan menunjukkan nilai kesalahan yang sangat kecil. Hal ini menunjukkan bahwa data gelombang hasil peramalan angin selama 10 tahun dapat digunakan di dalam penelitian ini. Hasil dari perhitungan arus sejajar pantai menunjukkan bahwa arus sejajar pantai yang terjadi di sekitar delta sungai Bodri dominan bergerak ke arah timur, bahkan besarnya sangat jauh.

Grafik mawar angin menunjukkan distribusi angin di perairan delta sungai Bodri tiap musim selama 10 tahun. Pada musim barat angin cenderung dari arah utara. Pada musim peralihan I, musim 
timur dan musim peralihan II angin cenderung bergerak dari arah tenggara. Hasil tersebut menunjukkan distribusi angin secara keseluruhan yang berhembus di perairan delta Bodri secara dominan dari arah selatan.

Hasil sebaran mineral feromagnetik yang diambil dari sedimen di perairan delta sungai Bodri paling besar terdeteksi di daerah sungai, yaitu sebesar 35,04\%. Di dekat muara sungai $11,59 \%$, di muara sungai sebesar $10,03 \%$ dan di depan muara sudah tidak terdeteksi kadarnya (0 \%). Di sisi timur, sebaran mineral feromagnetik terdeteksi walaupun tidak besar hanya sekitar $2 \%$ dan yang cukup tinggi terletak di bagian barat, yaitu 5,45\% pada stasiun 3 dan 2,21\% distasiun 2 serta $4,75 \%$ pada stasiun 1 . Hasil ini menunjukkan kadar mineral feromagnetik berasal dari arah sungai karena kadar tertinggi berada di dalam sungai dan semakin ke arah muara cenderung berkurang, bahkan selepas muara sudah tidak terdeteksi kadarnya. Angka ini kembali naik pada sisi barat dan timur delta dengan kadar yang paling besar terdapat di daerah barat.

Jenis ukuran sedimen di sungai, yaitu pada stasiun 7 dan 12, dominan berbentuk pasir. Semakin ke muara ukurannya semakin mengecil, bahkan di muara sungai, tepatnya pada stasiun 4,6 dan 8 jenis sedimen adalah lanauan dan kembali lagi berbentuk pasir pada stasiun 5. Pada bagian barat (stasiun 1, 2 dan 3) serta timur (stasiun 9, 10 dan 11) delta jenis sedimen hampir sama, yaitu dominan berbentuk pasir. Ukuran sedimen yang bersifat pasir menunjukkan bahwa arus di area tersebut cukup besar, dibandingkan dengan di muara yang sedimennya cenderung berjenis lanau yang menandakan pada muara delta Bodri arus yang terdapat disana cukup kecil. Sebaran ukuran butir ini menandakan ukuran mineral feromagnetik besar, serta termasuk ke dalam mineral berat dan keras.

Pola sebaran mineral feromagnetik ini menunjukkan, sedimen yang berasal dari sungai tertranspor ke sisi barat maupun timur oleh pengaruh arus sejajar pantai. Hal ini dikarenakan, hanya sedimen yang berukuran cukup besar (pasir) yang terdapat di wilayah barat dan timur. Karena hanya sedimen yang berukuran cukup besar yang dapat terdeposit di tempat yang memiliki aliran kuat. Hal ini sesuai dengan pernyataan Briggs (1977), bahwa semakin besar arusnya, maka sedimen yang terdeposit di area itu akan semakin besar. Begitu pun sebaliknya, apabila aliran air di area tersebut kecil, maka ukuran sedimen di area tersebut juga cenderung berukuran lebih kecil. Hal ini sejalan dengan penelitian Atmodjo (2010), yang telah dilakukan sebelumnya bahwa gelombang dan arus sejajar pantai merupakan faktor paling dominan dalam sebaran sedimen serta pembentukan morfologi di delta bodri.

Kadar mineral feromagnetik di bagian barat lebih besar dibandingkan di daerah timur, karena pada masa lampau tepatnya pada tahun 1864, muara sungai Bodri letaknya lebih ke barat (Bird et al., 1980 dalam Sanjoto et al., 2012). Sejak saat itu, diketahui letak muara sungai Bodri bergeser terus ke arah timur hingga saat ini. Pada tahun 2004, bentuk delta masih sangat jelas terlihat, dengan muara sungai terbagi menjadi 2 bagian, yaitu bagian yang mengarah ke barat dan ke utara. Pada muara sungai yang menghadap ke barat, letaknya persis di depan stasiun 1 , sehingga terjadi peningkatan kadar mineral feromagnetik secara anomali pada titik ini. Dapat disimpulkan pengaruh utama sebaran mineral feromagnetik di wilayah delta sungai Bodri adalah perubahan morfologi delta dan arus sejajar pantai.

\section{KESIMPULAN}

Hasil penelitian tentang mineral feromagnetik di wilayah delta sungai Bodri dapat disimpulkan, bahwa kandungan mineral feromagnetik di delta sungai Bodri terdeteksi paling besar $35 \%$. Pola sebaran kandungan mineral feromagnetik pada sisi timur sekitar $2 \%$, pada sisi barat 2-5\%, bagian muara hampir tidak terdeteksi dan bagian sungai terdeteksi hingga $35 \%$. Pola sebaran yang terbentuk menunjukkan bahwa sumber mineral feromagnetik berasal dari influk sedimen dari sungai. Disamping itu, faktor oseanografi yang berpengaruh paling dominan terhadap sebaran feromagnetik adalah arus sejajar pantai.

\section{DAFTAR PUSTAKA}

Atmodjo, W. 2010. Sebaran Sedimen di Perairan Delta Sungai Bodri, Kendal, Jawa Tengah. Laporan Penelitian. Jurusan Ilmu Kelautan, Fakultas Perikanan dan Ilmu Kelautan, Universitas Diponegoro, Semarang.

Bird dan Ongkosongo. 1980 dalam Sanjoto, T.B., S. Anggoro dan A. Hartoko. 2012. Kajian Perubahan Spasial Garis Pantai sebagai Zonasi Tata Ruang Pesisir (Studi Kasus Pesisir Kabupaten Kendal). Tata Loka 14(1):1-12. 
Briggs, D. 1977. Source and Methods in Geography: Sediments. England: Butterwords.

Gunawan, H. dan Arif B. 2014. Penentuan Persentase dan Nilai Suseptibilitas Mineral Magnetik Bijih Besi yang Berasal dari Tiga Lokasi Tambang Bijih Besi di Sumatera Barat. Jurnal Fisika Unand 3(4):249-254.

Handoyo, G. dan A.A.D. Suryoputro. 2015. Kondisi Arus dan Gelombang Pada Berbagai Kondisi Morfologi Pantai di Perairan Pantai Kendal Provinsi Jawa Tengah. Jurnal Kelautan Tropis 18(1):33-37.

Moriasi, G. N., J. G. Arnold, M. W. V. Liew, R. L. Bingner, R. D. Harmel and T. L. Veith. 2007. Model Evaluation Guidelines for Systematic Quantification of Accuracy in Watershed Simulations. Transactions of the ASABE 50(3): 885-900.

Revia, R.A., and M. Zhang. 2015. Magnetite Nanoparticles for Cancer Diagnosis, Treatment, and Treatment Monitoring : Recent Advances. Material Today (608) : 12.

Sugianto, D.N. 2013. Model Distribusi Kecepatan Angin Dan Pemanfaatannya Dalam Peramalan Gelombang Di Laut Jawa. Program Doktor Teknik Sipil. FT Undip. Semarang

Sugiyono. 2009. Metode Penelitian Kuantitatif, Kualitatif dan R\&D. Bandung : Alfabeta.

Triatmodjo, B. 1999. Teknik Pantai. Yogyakarta : Beta Offset.

Yulianto, A.S., Bijaksana dan W. Loeksmato. 2002 dalam Gunawan, H. dan Arif B. 2014. Penentuan Persentase dan Nilai Suseptibilitas Mineral Magnetik Bijih Besi yang Berasal dari Tiga Lokasi Tambang Bijih Besi di Sumatera Barat. Jurnal Fisika Unand 3(4):249-254. 